\title{
THE ROLE OF RECIPIENT QUESTIONS IN ESTABLISHING INTERSUBJECTIVITY AND PROGRESSING A STORY IN AIDED COMMUNICATION
}

\author{
Patricia Mayes \\ University of Wisconsin-Milwaukee \\ mayes@uwm.edu \\ Mary Clinkenbeard \\ North Central College \\ mclinkenbeard@noctrl.edu
}

\begin{abstract}
We report on a case study involving two participants: One participant has a communication disability and uses a high-tech, electronic device to speak, and the other is nondisabled. Their interaction differs from typical, everyday conversation because some linguistic resources are unavailable in aided speech, resulting in frequent repair sequences and slower progression. The analysis shows that when the aided speaker initiates an extended telling, the recipient uses questions to do repair-related actions as well as actions that could progress the story. Thus, this context affords the opportunity to investigate how the recipient's projections interact with intersubjectivity and progressivity.
\end{abstract}

Key words: Questions, progressivity, projection, aided communication, storytelling

\section{Introduction}

Recipients' questions are an important resource for clarifying a prior speaker's utterance. This is particularly true when one of the conversational participants has a complex communication disability, which is the context for the case study reported on in this paper. More specifically, we examine how an unaided (nondisabled) recipient's use of questions progresses the speaker's actions in interaction with a participant whose speech is aided by a high-tech device. 
Augmentative and Alternative Communication (AAC) refers to methods that aid or augment the speaking or writing of people with communication disabilities such as cerebral palsy and amyotrophic lateral sclerosis (ALS), and includes both low-tech (e.g., spelling out words on an alphabet board) and high-tech (e.g., electronic speech generation) methods. The focus here is on high-tech AAC, in which the aided participant types an utterance into a device, equipped with speech-generating software that then vocalizes what was typed. In this kind of interaction, some of the linguistic resources that typically would be used by a recipient to project the speaker's action are unavailable, resulting in frequent communication breakdowns, repair sequences, and slower progression of the ongoing project. This creates a context in which recipients frequently ask questions, in some cases aimed at repair and in other cases aimed at progressing the conversation. This study examines how these recipient actions affect the development of a story initiated by an AACusing speaker. Our analysis concerns what the recipient's questions reveal about projecting what comes next and how different types of questions affect progressivity, which has been shown to be a pervasive general preference in conversation (Lerner 1996, Schegloff 2007, Stivers \& Robinson 2006).

AAC interaction differs from typical everyday interaction in a number of ways. For example, due to the need to type everything before it is voiced by an AAC device, the timing of utterances differs from that of everyday spoken interaction, essentially meaning that utterances are produced slowly, and there are many inter-turn delays (Higgenbotham \& Caves 2002, Bloch \& Wilkinson 2004, Bloch 2011). In addition, factors like typing errors or traces of words or letters that are no longer relevant to the current utterance but remain on the AAC screen often lead to trouble sources and frequent repair. However, unlike repair in everyday interaction, repair in AAC interaction involves a lot of other-initiation and collaboration between speaker and recipient (Bloch \& Wilkinson 2004, 2009, Mayes Forthcoming, Müller \& Soto 2002). Indeed, the very same issues that lead to repair may also affect a speaker's ability to execute self-repair (Perkins 2003). The delays and frequent repairs affect topic maintenance (Higginbotham \& Caves 2002) and topic shifts (Bloch 2011). For example, it is not uncommon for recipients to lose track of the sequential context of AAC utterances, especially when there has been a topic shift, which often leads to repair work oriented toward identifying the current utterance's relation to previous talk or topics (Bloch 2011).

An additional factor in AAC utterance production is that the synthetic voices employed in such devices lack the prosodic features of natural language. For example, AAC devices may not have the option of raising intonation, commonly used to show that a speaker intends to continue their turn at the end of a turn construction unit (TCU), so interlocutors must closely monitor AAC-using speakers for clues as to where a TCU has ended before acting on what the speaker has said (Bloch 2011). 
All of the factors discussed so far significantly affect participants' achievement of common ground or intersubjectivity, not only with respect to an ongoing TCU but also across turns. Indeed, these issues may be exacerbated in extended projects that often consist of more than one TCU such as stories, which may be particularly difficult for an AAC-using participant to manage. Constructing sequential components such as story prefaces and descriptions of characters and settings, can take a lot of time and energy. Moreover, AAC-using participants may have trouble referencing previously discussed information, due to the timing delays discussed above (Higginbotham \& Caves 2002). In this context, recipients often take a more active role, collaborating with the AAC-using speaker in order to execute repair, as well as doing what Bloch (2011) refers to as "anticipatory other-completion," in which the recipient completes the speaker's turn.

The difficulty of achieving intersubjectivity also affects progressivity (Heritage 2007). Indeed, in examining how conversational participants achieve intersubjectivity with respect to recognitional reference, Heritage (2007) argues that intersubjectivity competes with progressivity in that there can be no forward progress when the recipient does not understand what the speaker is referring to. However, he goes on to point out that, "[a]bsolute security of reference is incompatible with progressivity," and participants must manage the linguistic resources for reference and repair in ways that strike a balance between these two principles (p. 261). To this end, participants treat recognitional reference as a responsibility that is shared between the speaker and recipients (Heritage 2007).

The link between intersubjectivity and progressivity brings up questions about how recipients project what comes next in the collaborative context of AAC interaction. Clearly, projection plays a crucial role in both repair and anticipatory completion, and one way to investigate recipient projection is by examining the linguistic resources recipients use to aid with achieving intersubjectivity and progression. As mentioned, recipients' questions can be an important resource for clarifying a prior speaker's utterance in any context, and they appear to be particularly useful in AAC interaction. We examine how the AAC-using participant in this study tells a story and investigate the following questions: 1) what types of questions does the recipient ask and how do those questions relate to whether the recipient is engaged in repair or an action oriented toward progression (e.g., anticipatory completion)?; 2) what can we learn about how the recipient projects what comes next?; 3) what kinds of actions does the speaker do immediately before and after the recipient asks a question, and does such sequencing affect the progress of the telling?

Essentially, our study provides further support for the importance of intersubjectivityin achieving progress and seemsto suggest that intersubjectivity wins out when these two conversational principles compete. Indeed, anything that disrupts intersubjectivity or common ground must be resolved before the ongoing activity continues. A crucial factor in achieving intersubjectivity in AAC interaction is the recipient's ability to project not only at the local level of 
turn construction but also at the more global level of understanding what sort of project the speaker is engaged in. Before discussing our analysis in more detail, we discuss previous work on projection, storytelling, and questions.

\section{Projection}

Projection refers to the ability to predict what is coming next based on "knowledge about how actions (or action components) are sequenced" in time (Auer 2005: 8). That sequential organization is a primary resource used by recipients to project the course of action as it unfolds has been well researched. (See e.g., Chevalier \& Clift 2008, Drew 1984, Schegloff 1990.) Other work points to the importance of syntactic structure (Auer 2005, 2009, Chevalier \& Clift 2008, Hayashi 2004, Helasvuo 2004). Auer (2005, 2009) argues that grammatical structure at various levels, including phonological (segmental), phrasal, and clausal, plays an important role in projection. Essentially, recipients use their knowledge of the structural patterning in their language to project what is coming next, and knowledge of syntactic hierarchy is key to this process. Thus, syntactic structure is a resource that recipients can use to project possible points of syntactic completion within a turn. However, time is another important factor in projection in that it is not clear how long particular forms can be remembered by the recipient and possibly even the speaker (Auer 2009).

Another resource participants use in projection is prosody. For example, in English, Ford and Thompson (1996) have found that prosody is linked to projecting completion points in a TCU, and Chevalier and Clifton (2008: 1743) have found that "the systematic placement of speech perturbations" (e.g., "sound stretches" and "the prolongation of a sound") play a role in projecting the action of an unfinished turn in French.

As discussed, natural prosody is not a feature of AAC utterances, and there are timing delays that might extend beyond the limits of memory. The lack of these resources may leave recipients confused about not only the immediate action, but also the larger trajectory of the ongoing project. In this context, recipients can use whatever resources are available to project what comes next. These include the speaker's gaze and gestures as well as already produced structural elements such as segmental and phrasal components, which can be useful in repairing any issues with the prior utterance. However, they are apparently less useful for projecting a longer trajectory and understanding the speaker's extended project. In that case, the recipient may ask questions designed to get more information about the speaker's ongoing actions.

\section{Storytelling}

We are interested in stories as a sustained action that often takes place over more than one utterance (Sidnell 2010). As discussed above, such projects may be difficult to manage in AAC interaction. As such, they tend to be co-constructed. However, when the recipient is "unknowing" (Goodwin 
1979), as in the data we examine, co-construction is more difficult. In this context, a primary resource the recipient can use to achieve intersubjective understanding and progress the story is questions. What is at issue here is how the recipient projects which questions are relevant.

Stories have been examined from many different perspectives in various fields, and how they are identified and defined has undergone many changes. For example, in sociolinguistics, early work viewed narrative as a textual product and focused on structural elements such as beginnings, complicating actions, resolutions and so on (Labov 1972). This traditional view also held that narrative was centered on past events and was the performance of a single teller, in which the teller had exclusive control over the positioning of the protagonist(s) (Ochs \& Capps 2001). On the other hand, conversation analysts have for some time put forth the view that stories are action-based projects, made up of more than one TCU that are produced through mutual cooperation between a teller and recipient(s) (Goodwin 1979, 1984, Mandelbaum 2013, Sidnell 2010). As such, stories are better understood as sequentially organized "tellings" that are shaped as conversation unfolds (Mandelbaum 2013, Ochs \& Capps 2001, Stivers 2008). In addition, Ochs and Capps (2001) and others working on so-called "small stories" have focused on how stories may concern future or hypothetical events and are often co-constructed by more than one participant in conversation (e.g., De Fina \& Georgakopoulou 2015, Georgakopoulou 2006, 2007, Goodwin 2015). As Ochs and Capps (2001: 2-3) put it, "The content and direction that narrative framings take are contingent upon the narrative input of other interlocutors, who provide, elicit, criticize, refute, and draw inferences from facets of the unfolding account."

Co-construction is a particularly relevant aspect of stories initiated by people with complex communication needs such as those who use AAC. Indeed, Goodwin (2015) shows how Chil, a man who has a three-word vocabulary due to a stroke, uses a combination of utterances, gestures, and other embodied actions to create sequentially meaningful contributions that prompt his interlocutors to "guess" at his story trajectory and thus participate in the co-construction of stories that Chil has initiated.

\section{Questions}

Questions and question-answer sequences have been well researched in various settings, including everyday conversation and many institutional settings. (See, e.g., Freed \& Ehrlich 2010, Hayano 2013, Heritage \& Clayman 2010, Stivers 2010, as well as Graf et al. this issue, for overviews.) Stivers (2010) argues that although questions are commonly framed as requests for information, speakers use conversational questions to accomplish a variety of social actions such as seeking agreement, doing confirmation requests, and doing repair work. Hayano (2013: 396) writes that questions "pressure recipients for response, impose presuppositions, agendas and preferences, and implement various initiating actions." Indeed, research in many institutional settings shows how question-answer sequences are instrumental in enacting institu- 
tional asymmetries, not only related to the knowledge differential (or "epistemic gradient") implied in asking a question (Heritage \& Clayman 2010: 25), but also due to asymmetrical patterns that afford or restrict the right to speak in terms of who can ask questions, who can answer, and under what circumstances. Still, Worsøe and Jensen (this volume) remind us that all interaction is also informed by everyday practices, and this can disrupt the normative patterning of question-answer sequences, as when clients in psychotherapy sessions direct questions to the therapist and end up changing the trajectory of the ongoing project.

Of course, another way such fluidity can be introduced in question-answer sequences is through the design of the question itself. For example, Tranekjær (this issue) shows how speakers in management positions use multifunctional questions in meetings with employees to accomplish different and even competing projects such as establishing intersubjectivity, encouraging employee input, and seeking compliance, all of which can lead in different directions, depending on the response.

In our study, although the interaction took place in an institutional setting, there was not a professional relationship between the participants, so there was not asymmetry associated with differing institutional identities. Yet, as will be shown, the point that the trajectory of a particular interaction or the ongoing project can change at any point is very relevant in the interaction we examine. Indeed, as mentioned, tellings are often comprised of multiple TCUs (or "multi-unit turns"), and during a telling, recipient questions may temporarily pause the progression of the telling (Koenig 2006). According to Koenig (2006: 24), story recipients use such questions (termed "oblique interventions") for various functions, including seeking "not provided for information, showing surprise, and challenging some aspect of the multi-unit turn so-far produced." Our project examines how recipient questions, while always delaying the immediate progression of the story, may also contribute to its ultimate progression by addressing the interlocutors' intersubjectivty and allowing the recipient to better project what will come next in the telling. However, as Koenig (2006: 67-72) attests to, recipient questions may also occasionally lead speakers to abandon their tellings, especially in cases where the trajectory of the conversation changes as a result of the question. We examine how the recipient's questions may be used as resources for projection and co-construction as well as obstacles that hinder the progression of a telling initiated by the AAC-using speaker. Our overarching goal is to show how the recipient of a storytelling uses various types of questions to do the interactional work of repair and projection in the co-construction of the story. We attend in particular to the ways that recipient questions orient to the progression of the unfolding telling, anaphorically focusing on repairing the previous talk, or cataphorically, projecting what may come next. 


\section{Participants, Data, and Method}

This is a single-case study of a 78-year old man with cerebral palsy (Fred) who uses a high-tech AAC device as his primary means of communication. The data consist of seven hours of video-recorded conversations in American English, collected over a six-month period in a care facility specializing in daycare for people of all ages with disabilities. The co-participant who interacted with Fred on a regular basis is Molly, a volunteer at the care center. Fred and Molly are friends, who had known one another for about ten years and regularly had conversations in which they chatted about everyday topics such as what had happened since they last saw each other. ${ }^{1}$

Over the two years prior to the study, Fred had been communicating with others using an iPad equipped with AAC software. ${ }^{2}$ This device generates speech after each word he types, and Fred can press a button to get the device to produce a string of typed words at any time. In addition, the device provides possible word choices while Fred types, and it pronounces words that are not necessarily contained in its memory, thus sometimes producing nonsense words. It also saves and presents previous entries that Fred has input. For example, if he types a string of letters, such as aboutthe with no space between about and the, the device will pronounce this string as though it were a unit. These aspects of the device's function sometimes become relevant factors in the conversation, at times allowing the participants to avoid confusion, and at other times creating issues with respect to intersubjectivity. The extracts presented here have been transcribed using the conversation analysis system (Jefferson 2004) with a few modifications for interaction involving AAC. (See the Appendix for the Transcription Key.) Following the practices of conversation analysis and interactional linguistics, the analysis focuses on sequential patterning.

\section{Recipient Questions and Co-constructed Tellings}

In what follows, we examine how the recipient used questions to help the AAC-using participant to tell a story that was not already known to the recipient. Following Stivers (2010: 2772), we define a question as a turn that is designed to seek "information, confirmation, or agreement," as opposed to turns that are syntactically constructed as interrogatives but do some other type of action. In particular, we focus on wh-questions and polar questions, including declarative, interrogative, and tag questions, because those are the types of questions that appear in our data.

First, we illustrate the functions of anaphorically-oriented and cataphorically-oriented questions in our data, and then we analyze extracts from a longer story that contains examples of both types of questions. We consider speaker and recipient actions, the recipient's projection strategies, as well as how the questions affect progressivity. 


\subsection{Two Functions of Recipient Questions}

In the context of AAC interaction, where progress is slow and there are many repairs, when an AAC-using participant embarks on a multi-unit turn at talk or an extended project such as a story, recipients often help construct the ongoing talk. In cases in which the recipient already knows the story, this task is likely to be more straightforward, but when the recipient does not know or has not already heard the story, the task can require a lot of interactional work and time (Luo et al. 2008). Recipient questions are a particularly useful resource in this context, and we noticed that the majority of such questions function in two ways. The first is oriented toward repairing the teller's prior utterance and is in that sense anaphorically oriented. These include primarily candidate understandings (e.g., you mean getting back to?) and other more general questions oriented toward reestablishing intersubjectivity (e.g., what subject are we on.). The second way that recipient questions function is to advance the speaker's ongoing telling, and thus, these questions are cataphorically oriented (e.g., oh they were in your closet so he had to go through a door, huh.). As will be shown, although these cataphorically-oriented questions may be designed to progress the story, sometimes they are unrelated and can potentially cause more delays in progress. A key factor is the recipient's ability to project what comes next.

Extract 1 shows anaphoric, repair-related questions and cataphoric questions, both apparently designed to progress the story. In 1, Fred is telling Molly about some cookies that were taken from his room at the group home where he lives.

(1) Cookies [00:52:47;27 - 00:53:03;14]

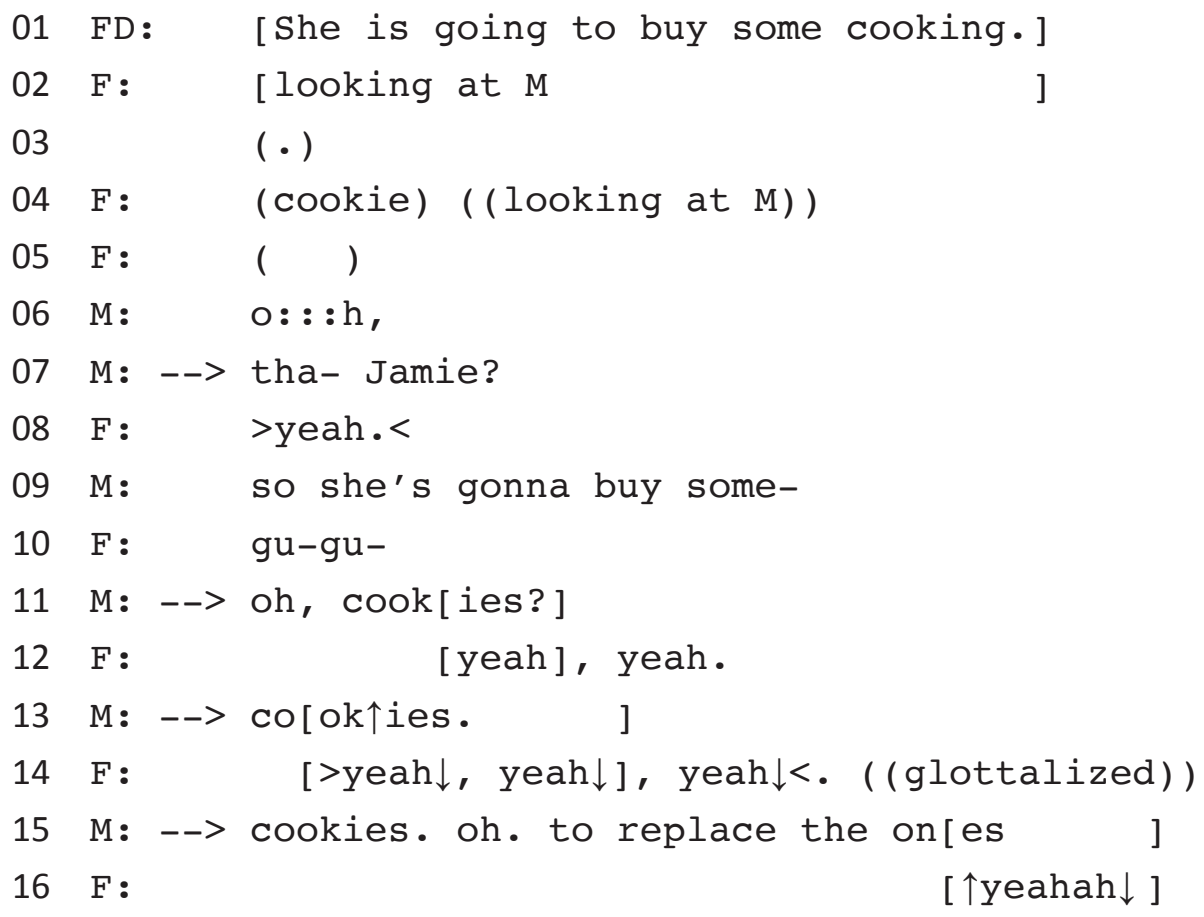


In our data, anaphoric questions all involved some type of repair of the previous talk, and indeed, most were other-initiations such as candidate understandings. In 1, the first candidate understanding Jamie? (line 7) targets the trouble source she (line 1). Fred confirms this understanding in line 8. In line 11, Molly produces another candidate understanding to repair the trouble source cooking (line 1). This understanding is confirmed by Fred in line 12 and again repeated (line 13) with additional confirmation (line 14). In line 15 , Molly produces a polar question that is cataphorically-oriented in that it progresses the story, supplying the purpose of the story character's action, something that had not yet been told. About a minute and a half later, Molly produces the utterance oh they were in your closet so he had to go through a door huh. This turn contains both a candidate understanding oh they were in your closet, targeted at Fred's prior turn (not shown here) and the question so he had to go through a door huh which progresses the story in that it reveals another character's prior actions that had not yet been told.

\subsection{Projection, Progressivity, and Recipient Questions}

In this section, we focus on a longer story that takes some time to get started, gets interrupted by other stories, and eventually comes to what may be considered an ending about fourteen minutes after the point where extract 2 begins. We break down the story to focus on segments in which the recipient's apparent attempts to progress a particular course of action through her questions sometimes are successful but other times lead in directions that apparently are tangential to the speaker's project. Extract 2, shows Fred attempting to launch "The Pops" story by returning to a topic that he and Molly had been discussing earlier, perhaps before recording began. During this conversation, Fred and Molly are seated next to each other, Fred in a wheelchair and Molly in a chair at a small table (see Figure 1). Fred's AAC device is positioned in front of him on the tray of his chair and he uses his left hand to type on the device with a stylus while his right arm is by his side. The device is positioned so that both participants can see the screen.

(2) The Pops [00:26:26;06 - 00:27:26;26]

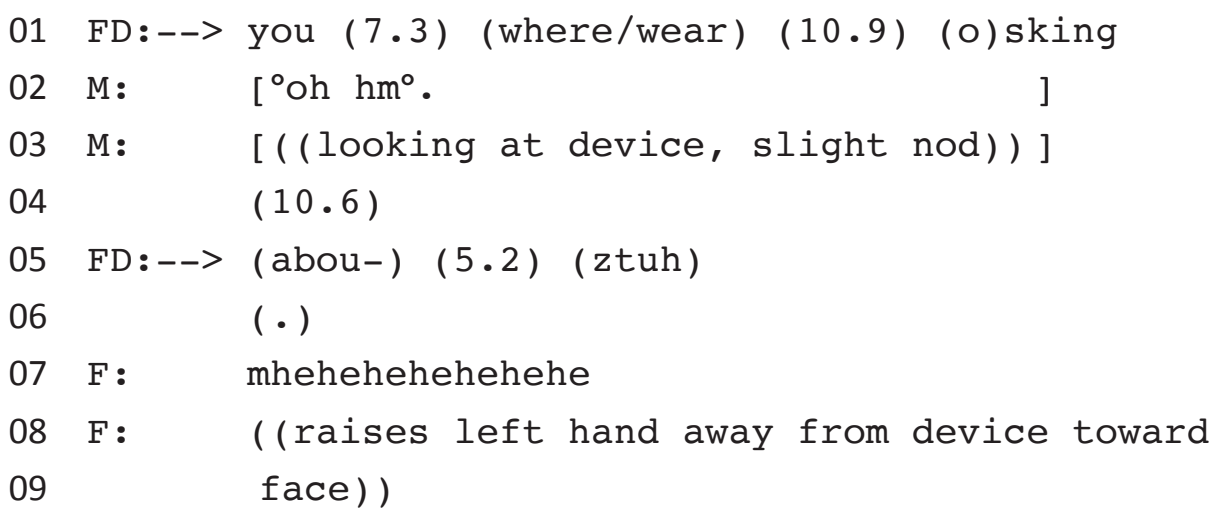




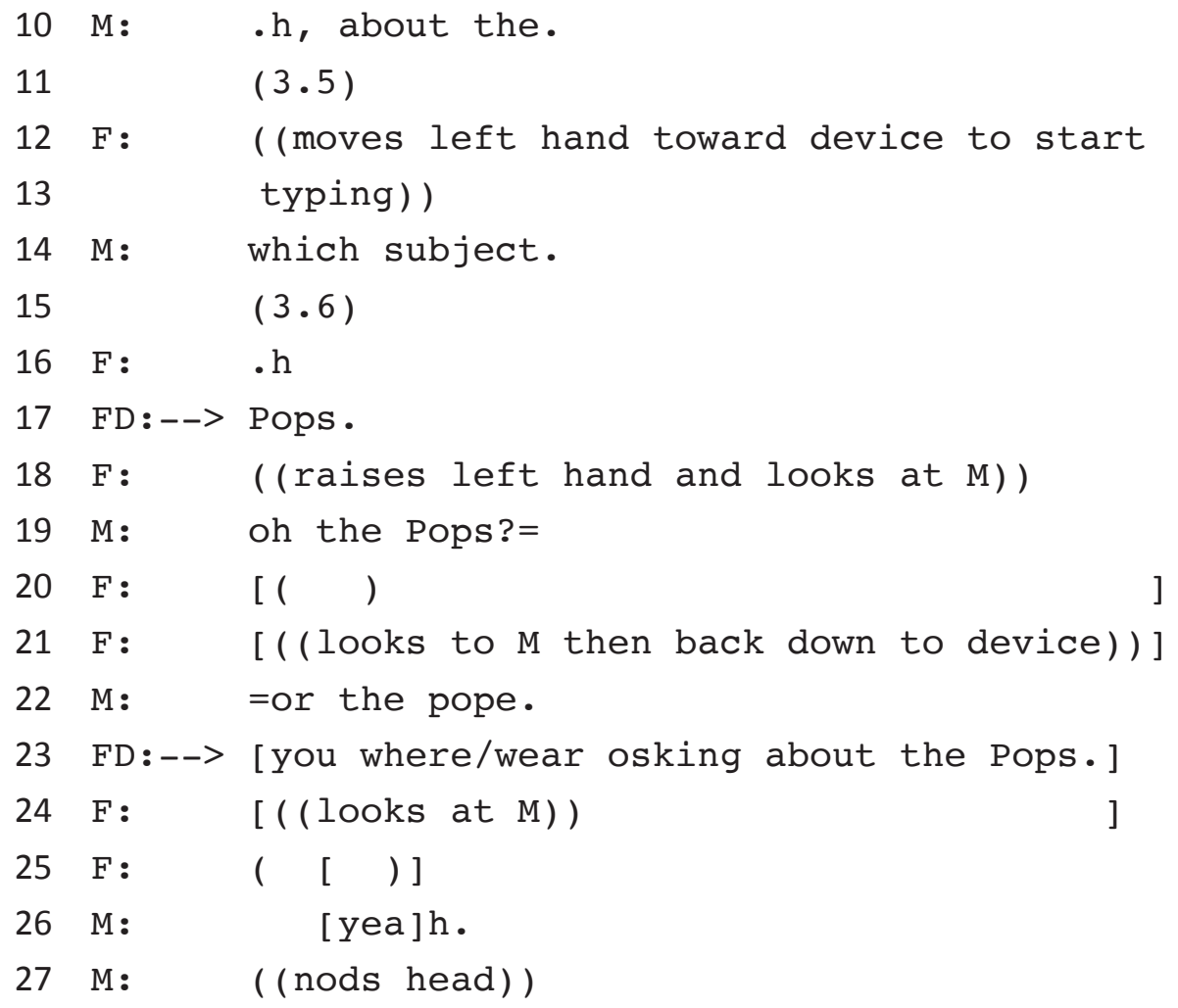

After several turns (lines 1, 5, and 17) and questions by Molly (lines 10, 14, and 19) designed to perform repair-initiating actions, Fred successfully produces a complete utterance in line 23, which is aimed at launching the story. Although story prefaces are sometimes more explicit (Mandelbaum 2013, Sacks 1978), announcements like the one in line 23 sometimes function to project stories (Sidnell 2010). In addition, tellers often mention aspects of the setting of the forthcoming telling (Mandelbaum 2013, Sidnell 2010), as Fred does in line 17 (and again, in 23) when he mentions the Pops, in reference to the "Pops" ('popular music') concert season of the local symphony orchestra. The utterance in line 23 seems to be a story-launching action, not only because of the information about the setting, but also because according to his account Fred is returning to a topic that the pair had been discussing previously. The return to this topic, thus, projects that Fred has something more to say about it, and that something could be a story. 


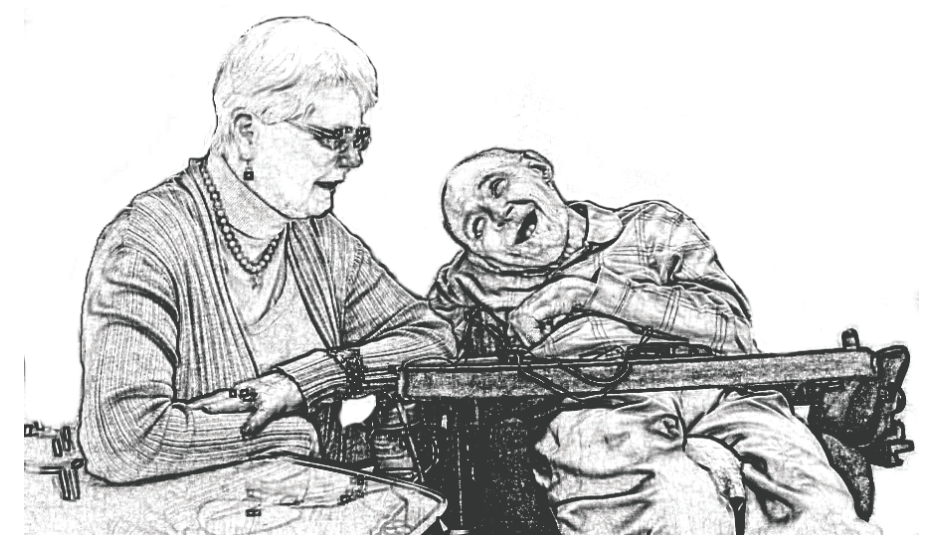

Figure 1. Lines 21-22.

As the AAC device voices the utterance (line 23), Fred gazes at Molly to register her understanding of his utterance.

In extract 3, which directly follows 2, Molly asks a general question that may be aimed at progressing Fred's action.

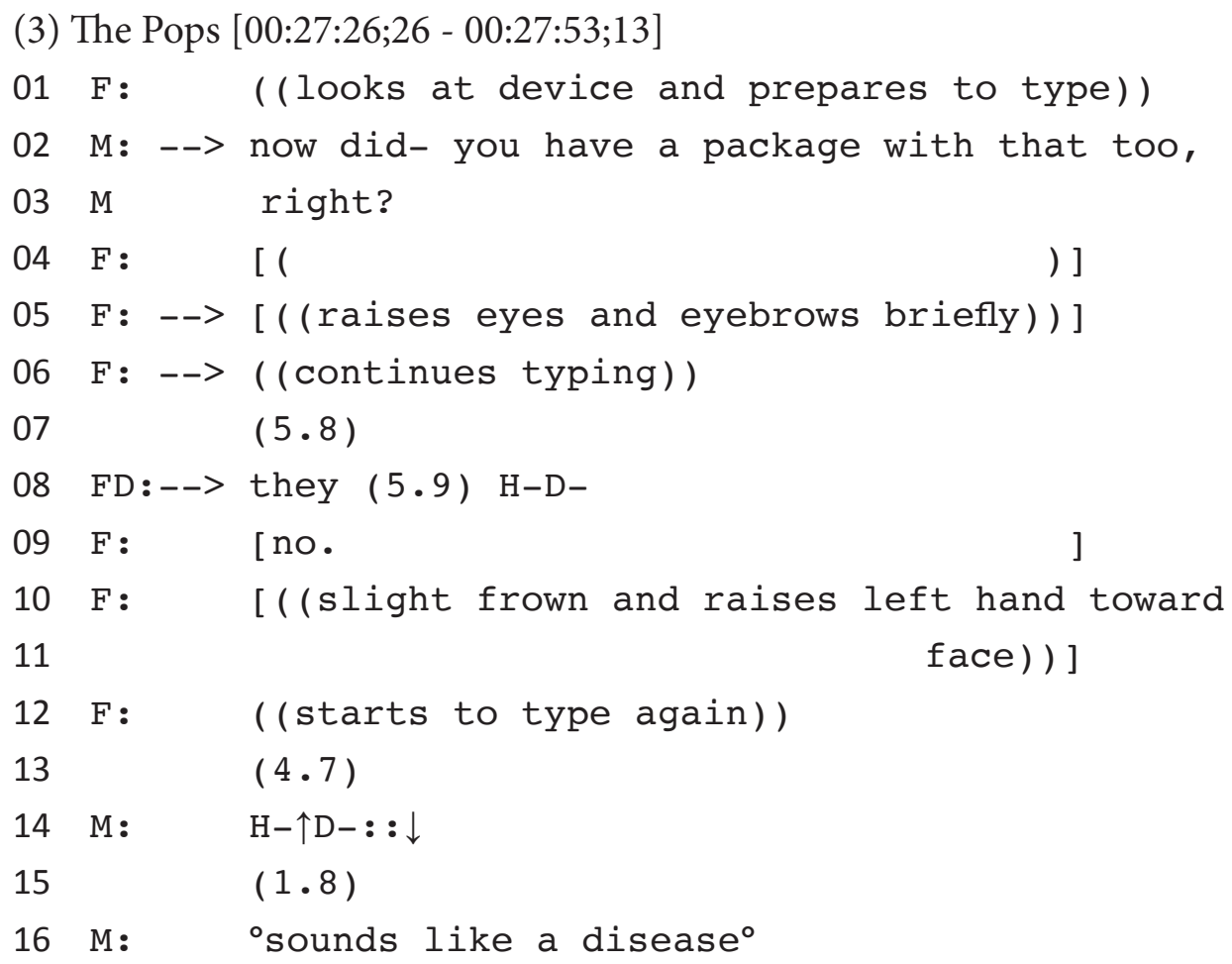


The question in lines 2-3 is quite general and might be oriented toward eliciting more background information. Indeed, at this point, Molly cannot project beyond the fact that Fred wants to say something about the Pops. At the beginning of this recording, Fred had been telling Molly about another type of entertainment package that his brother had purchased for him. It is possible that Molly assumed that Fred was returning to the topic of entertainment packages, this time with reference to the Pops. On the other hand, it is also possible that this question is oriented toward obtaining information that Molly was interested in. In any case, Fred gives only a minimal response that seems to be affirmative (lines 5-6) and continues typing his next utterance (voiced in line 8). Fred's minimal response includes slightly raising his eyes and eyebrows briefly while continuing to maintain his bodily orientation toward typing on the device (see Figure 2). Fred's actions manage the focus of the interaction keeping attention on what he is composing on the device and limit the trajectory of Molly's question from progressing further.

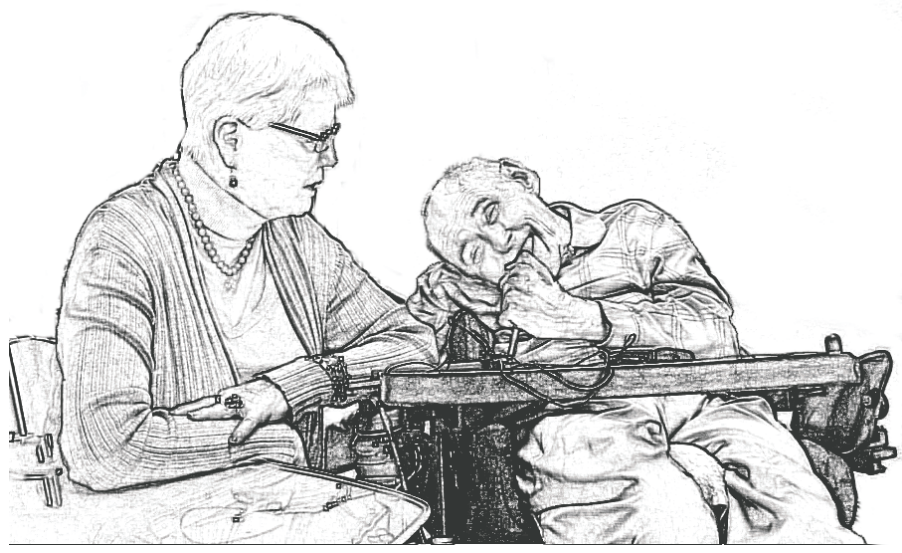

Figure 2. Lines 5-6.

Line 8 contains the trouble source $H-D$, voiced by the device as $\langle\mathrm{h}\rangle\langle\mathrm{d}\rangle$, and both participants initiate repair, Fred with a vocalization and facial gesture (lines 9-11), and Molly by repeating the trouble source and making a small joke about it (lines 14 and 16). We should note that short vocalizations such as the word no in line 9 have been referred to as "repair prefaces," which is "the segment positioned between the repair initiation, if there is one, and the repair solution" (Keevallik 2012: 127). In AAC interaction, however, because there are so few resources available for self-initiation of repair, aided participants' vocalizations of no seem to function as repair initiators, along with other actions, such as eye gaze, gestures, and laughter. ${ }^{3}$

Subsequently, Fred is able to complete the repair himself and eventually produces the utterance they had two person who imprint. The word imprint is another trouble source. In response, Molly tries to initiate repair, using the 
open class repair initiator what (Drew 1997) and a question that targets the trouble source that's not what you wanted to say? Then, she begins to ask more questions, some focused on the repair and thus anaphorically oriented, and others focused on progressing the talk and thus cataphorically oriented. This is shown in 4 .

(4) The Pops [00:29:55;22 - 00:30:49;02]

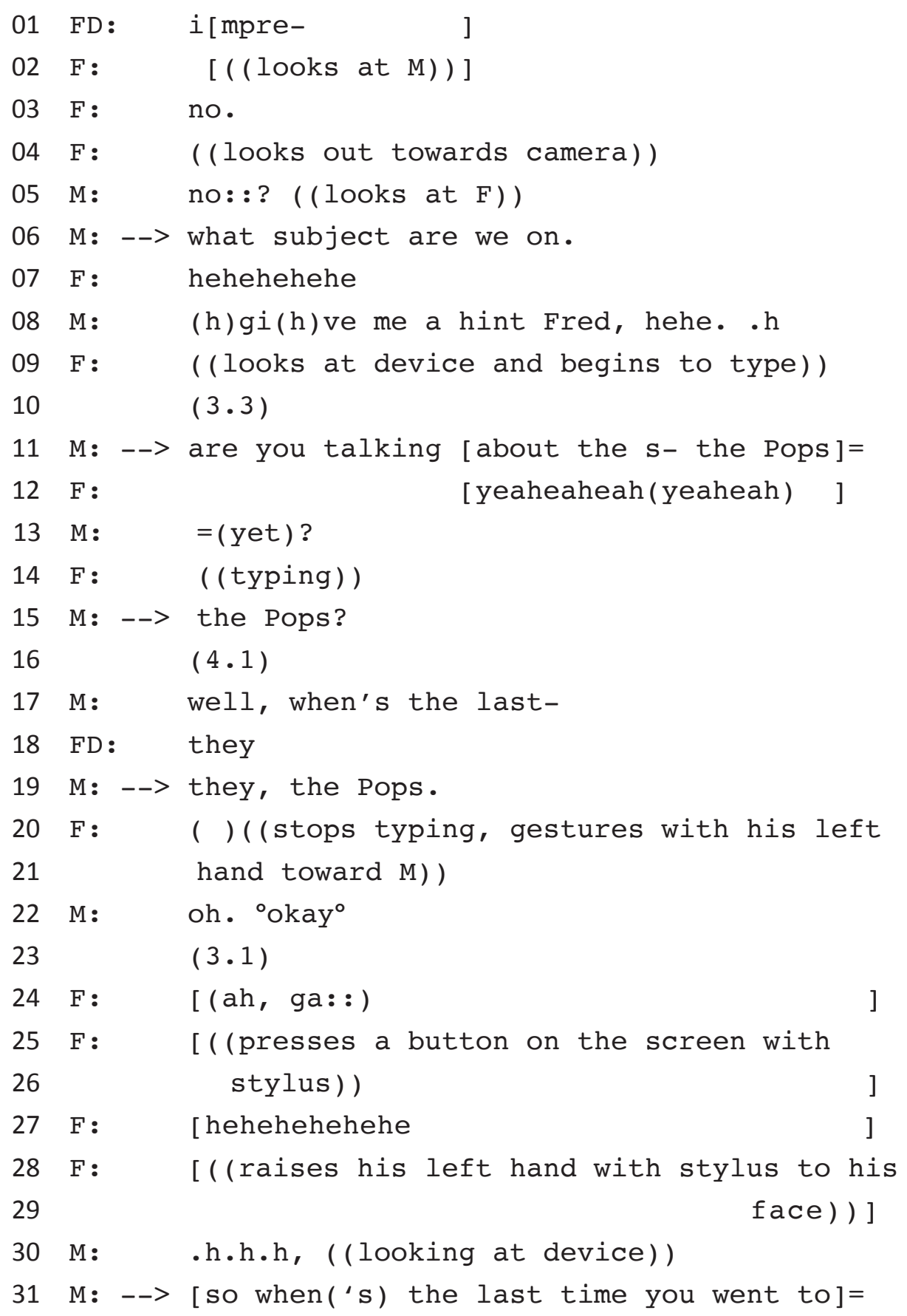




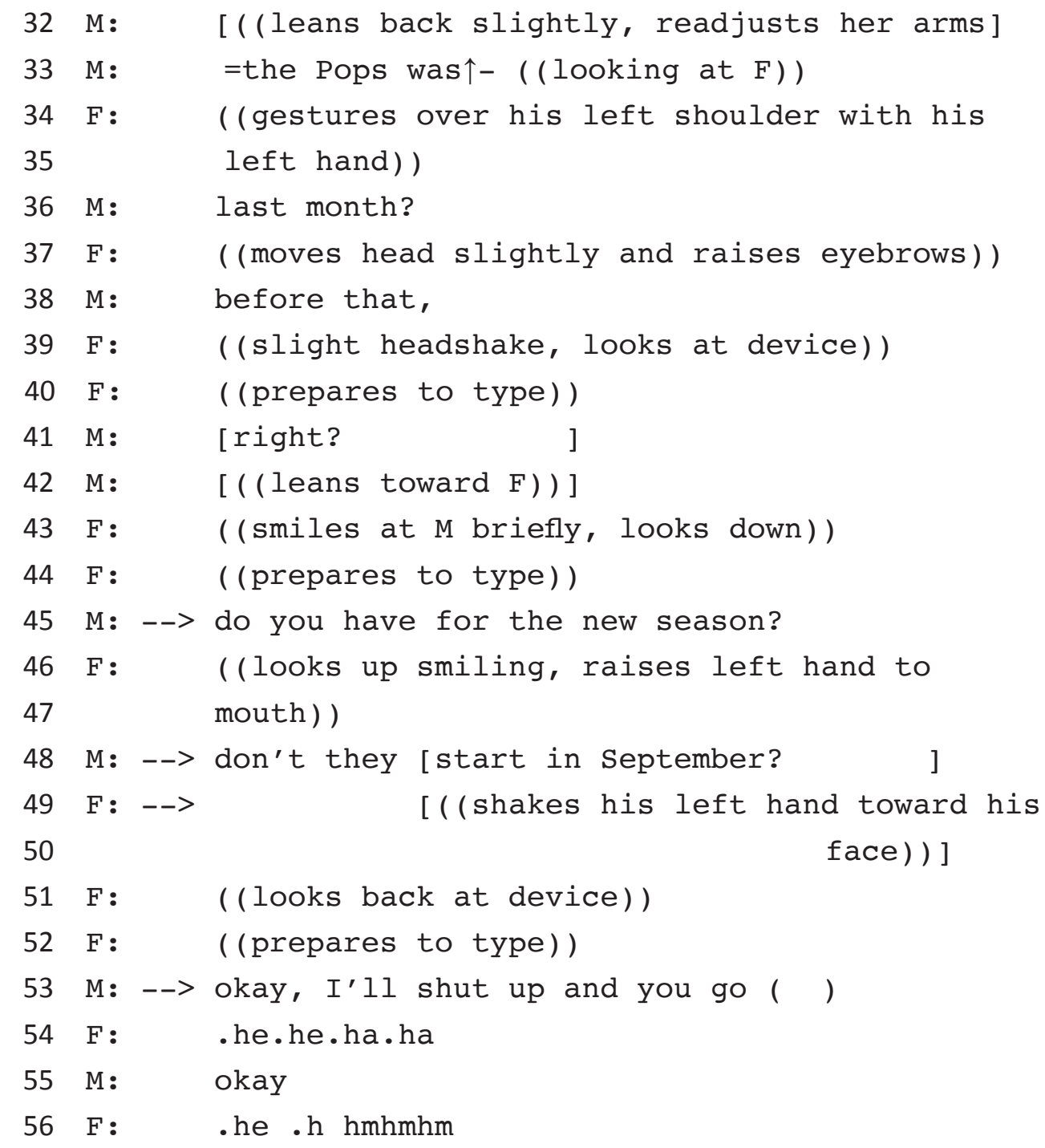

In line 1, Fred begins to repair the original trouble source imprint (not shown in 4), and looks at Molly (Figure 3). Such gaze shifts when a trouble source occurs often prompt the recipient to produce candidate understandings and may be requests for assistance in completing the repair. 


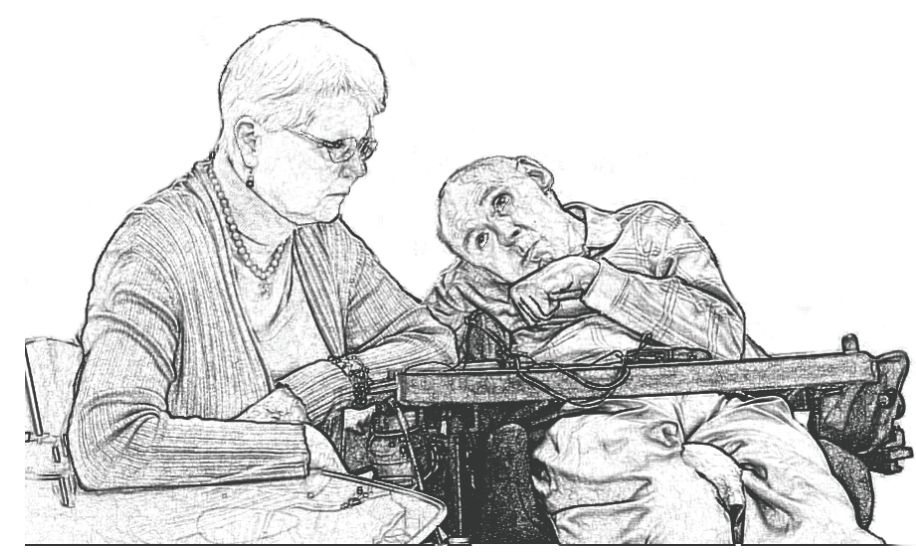

Figure 3. Line 1-2.

However, in this case, Molly is not able to project what word Fred is looking for. Although there is some structural information available in the form of a partially complete sentence (they had two person who) and five phonological segments (line 1), these elements do not seem to fit together in a way that allows prediction of an appropriate form, and Molly appears to have lost the thread of the conversation. This leads her to produce the general wh-question what subject are we on in line 6. She follows this in line 11 with a more specific question that targets the topic they had been discussing just prior to the trouble source. Despite Fred's emphatic confirmation that the Pops is still the current topic (line 12), there appear to be difficulties in maintaining intersubjectivity, as evidenced by the fact that Molly seeks another confirmation at line 15 and then in line 19, questions whether the pronoun they in line 18 refers to the Pops. These ongoing issues with recognitional reference also seem to be due to the fact that Molly is unable to project what Fred wants to say about the Pops. This example shows the point made earlier that the slow development of actions and sequences in AAC interaction makes projection at the level of sequential organization difficult. After Molly's confirmation request in line 19, Fred momentarily stops his typing, gestures toward Molly with his typing hand, and produces a vocalization with a tone hearable as negative affect. Molly notes Fred's actions with a change of state token oh and a quiet okay (line 22). After a 3.1 second pause, Fred produces another vocalization and presses what is likely the erase button deleting the utterance he had been working on constructing (Figure 4). 


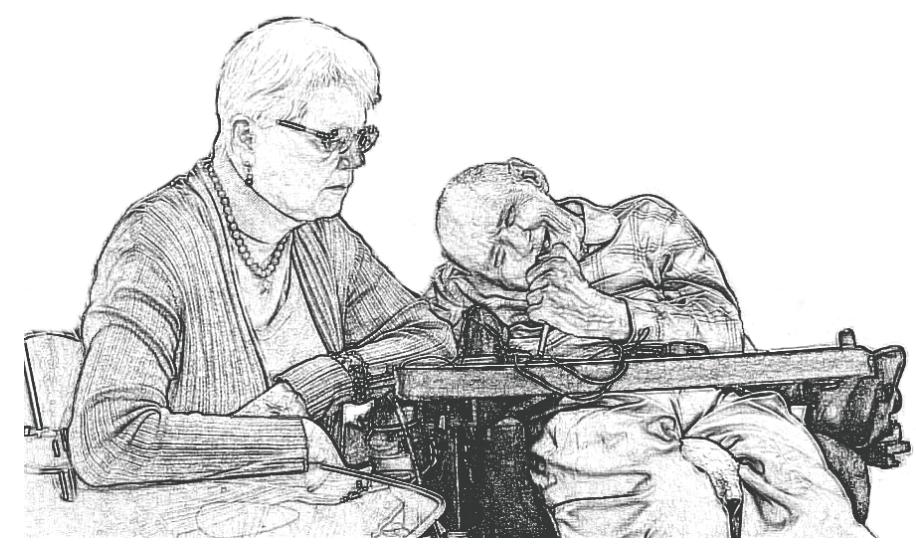

Figure 4. Lines 24-26.

When Fred stops typing, Molly shifts her body position by leaning back slightly and looking at Fred while beginning a series of questions starting in line 31 . Molly's difficulty projecting what Fred might be saying is perhaps what leads her to ask these general questions, concerning when Fred had attended the Pops concert (lines 31 and 33), whether he would attend in the new season (line 45 ), and when the new season would begin (line 48). Such general questions might be an attempt to find a connection that could improve projectability, but they can also be distractions that cause further delay, impeding progress and making projection even more difficult. Indeed, as Auer (2009: 186) points out, "It is unclear ... how long a projection can be 'in play' in dialogical interaction before it is forgotten by the speaker, the recipient, or both." Fred's minimal or non-responses to some of the cataphorically-oriented questions Molly produces seem to suggest that he also understands that Molly is using these questions to try and connect what has been said so far, which would allow her to further project the trajectory of Fred's telling. Since questions project a second pair part and produce "sequential implicativeness" (Sacks, Schegloff, \& Jefferson 1974, Schegloff 2007), Fred's minimal or nonresponses to some of Molly's cataphorically-oriented questions suggest that he understands her questions as potentially supplemental to the action at hand: the progression of his story.

Fred's embodied actions provide additional resources for Molly's projection. He responds to her question so when('s) the last time you went to the Pops was (lines 31 and 33) by gesturing with his left hand pointing over his left shoulder (lines 34-35). Molly's candidate understandings of his gesture are last month? (line 36) and, when this does not seem to be the answer Fred is looking for, before that (line 38). Fred then prepares to start typing on the device (lines 39-40), but Molly continues to ask questions (lines 41, 45, and 48). Rather than responding affirmatively or negatively to the polar questions Molly produces in lines 45 and 48, Fred shakes his left hand and moves it toward his face (Figure 5), a gesture that could indicate that it is his turn to talk. 


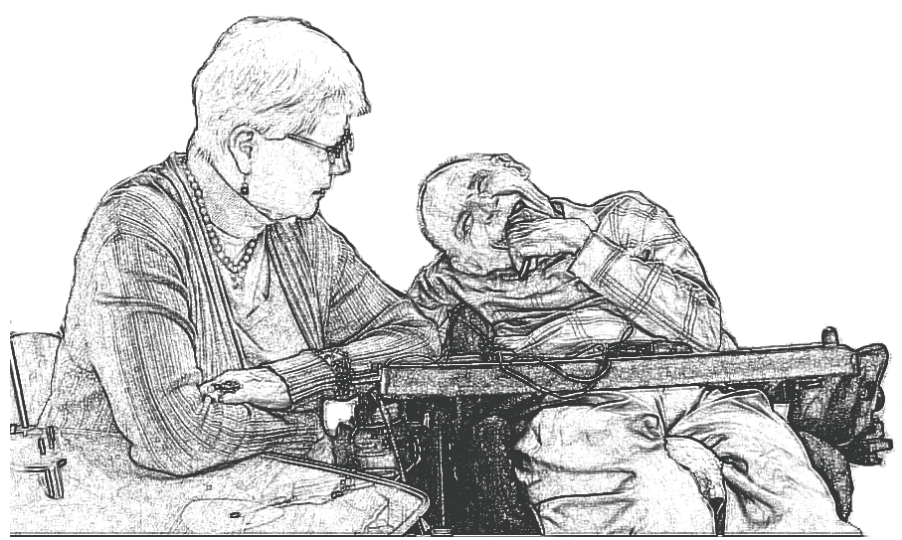

Figure 5. Lines 48-50.

Molly's line 53 utterance in 4 acknowledges that too many questions from her may slow the progress of the interaction, but toward the end of the next extract she resumes the strategy of asking general questions.

(5) The Pops [00:31:01;05 - 00:31:34;02]

$01 \mathrm{M}$ : so we're talking about the Pops?

02 F: ((gestures with left hand))

$03 \mathrm{M}$ : right?

$04 \mathrm{~F}: \quad$ ((prepares to type))

$05 \quad(2.7)$

06 M: which you have tickets to

$07 \mathrm{~F}:$.h ( ) ((slight head movement))

$08 \mathrm{M}$ : or John does.

$09 \quad(\cdot)$

$10 \mathrm{M}$ : John [and you?]

11 FD: [las ]

$12 \quad(4.1)$

$13 \mathrm{~F}: \quad \cdot \mathrm{h}$

14 F : [.h( (sniff $))]$

15 FD: [week. ]

$16 \mathrm{M}$ : ${ }^{\circ} \mathrm{Oh}$ last week $^{\circ}$

17 FD: las [week. ]

$18 \mathrm{M}: \quad[(($ looks at $\mathrm{M}))]$

19 F: (yea:h.)

20 M: --> you went last week. 


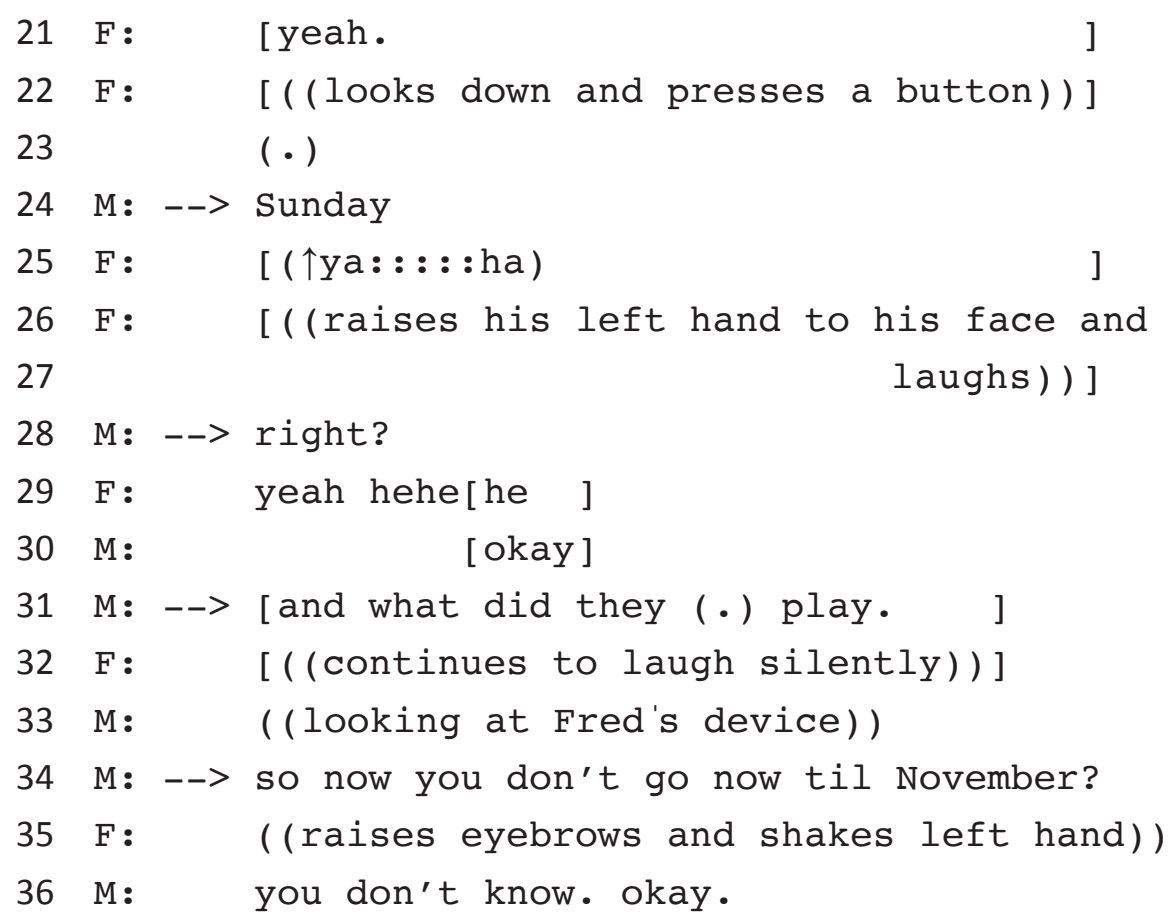

It is interesting to note that prior to asking more general questions, in lines 1-9, Molly recaps what she has understood about the trajectory of the interaction to this point. Although these utterances appear to be polar questions in terms of their intonation and because Molly glances at Fred as she is speaking, he only responds once with a slight head movement and vocalization in line 7 and continues typing. Thus, Molly's utterances may be designed to counter the possibility of forgetting and to assess intersubjectivity, by taking stock of the shared knowledge that had accumulated so far. While Molly was recapping the story, Fred had been typing, and subsequently produces another piece of information about the timing of the event (lines 11-17). In line 20, Molly produces a confirmation request, which Fred confirms (line 21). This question is thus anaphorically oriented in that it simply recaps already presented information, but after that, Molly shifts her focus to cataphorically-oriented questions involving information that had not yet been presented. In lines 24 and 28, she asks about the specific day that Fred had gone to the Pops, which Fred confirms (lines 25 and 29). 


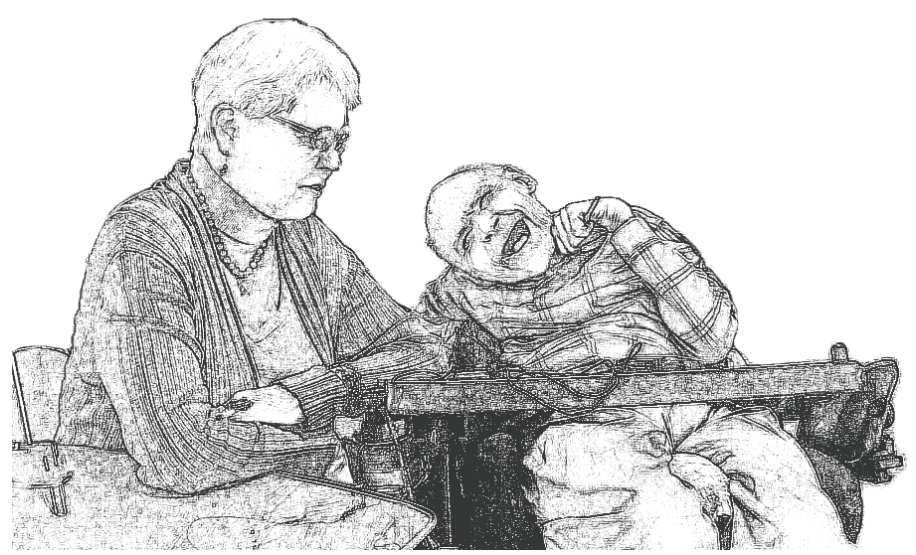

Figure 6. Lines 32-36.

Then, she asks two more cataphorically-oriented questions (lines 31 and 34) that are more general and may be oriented toward helping progress the ongoing telling. Fred does not respond to these questions and instead laughs (Figure 6) and then produces facial and hand gestures, which Molly understands as indicating that he does not know the answer to these questions and perhaps more generally that these questions do not relate to the trajectory of the ongoing telling. As was noted with respect to extract 4 , such minimal responses or nonresponses are one way that Fred can control the trajectory of the developing story to a certain extent and reign in the tangential trajectories that might develop otherwise.

With respect to projectability, although the question in lines 24 and 28 Sunday right? might be predictable from Molly's prior knowledge of when Fred generally attends Pops concerts, it is not projectable from the talk that had been produced prior to that point. Similarly, for the questions in lines 31 and 34, Molly seems to be relying on general knowledge of the context rather than prior utterances: In the case of what did they play, it is obvious that the orchestra played something at the concert, and in the case of so now you don't go now til November?, because the current conversation was taking place in October, Molly is able to guess that the next concert is likely to be at least a month away. It is possible that such tangentially related questions function to narrow down the topic through a process of elimination. Indeed, one strategy might be to eliminate what is not relevant in order to project what might be relevant.

In the next part of the interaction, Molly asks Fred to tell another, related story about who he attends the Pops concerts with. ${ }^{4}$ Fred complies with this request and then immediately turns back to the Pops story he had been trying to tell, as shown in extract 6 . 
(6) The Pops [00:37:32;05 - 00:37:49;06]

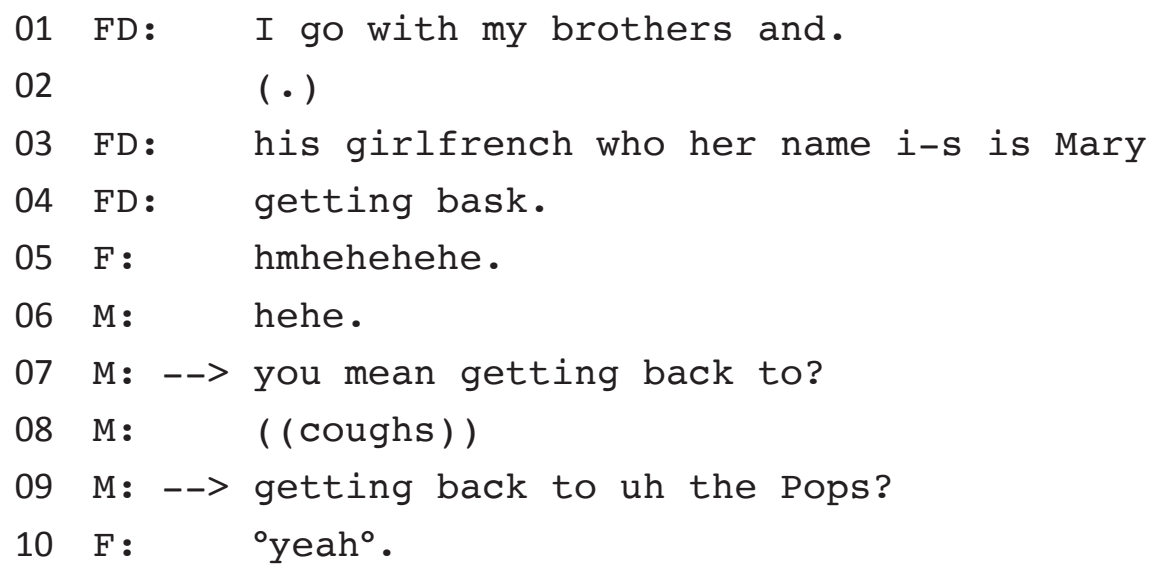

Although there are several typos and other errors in Fred's utterance (lines 1 -4), Molly does not initiate repair on anything but the last part. Indeed, both participants laugh, as is often the case when the device voices an utterance with errors or nonsense forms (see Figure 7).

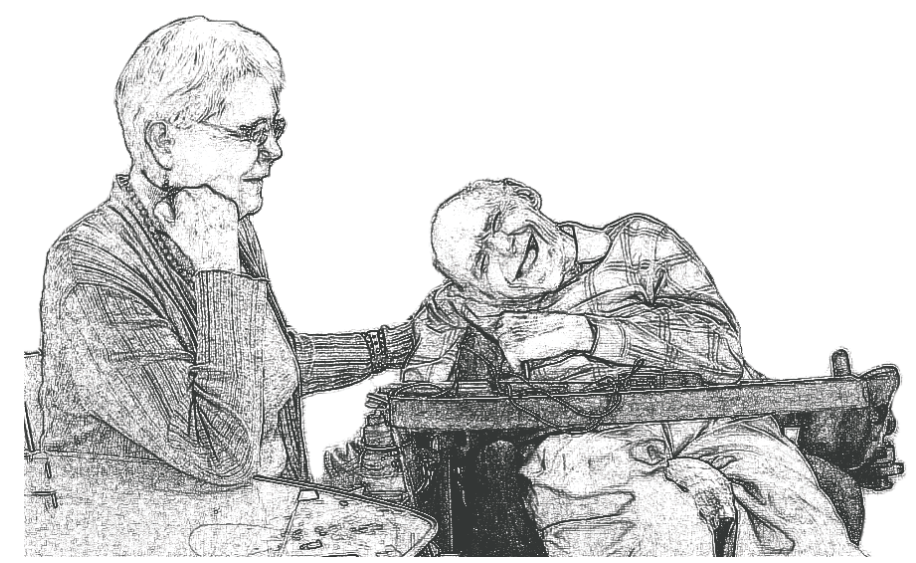

Figure 7. Lines 5-6.

Molly does initiate repair on the last part of the utterance getting bask, using a candidate understanding that corrects the erroneous form (line 7). She follows this with a second candidate understanding that includes the missing noun phrase the Pops. In this case, it seems that she is able to project this repair based on the existing structural information in the form of phonological segments: The word getting is well formed, and it is relatively easy to predict that bask should be back because bask only includes one extra phonological segment. Likewise, the next word to is predictable in this slot due to the fact that getting back to is a relatively common formulaic expression used to return to a previous topic. At this point, Molly has enough information to project 
that what follows is a noun phrase that fills the blank in the phrase getting back to Based on the fact that the prior topic that the participants had been discussing for over ten minutes was the Pops, it is relatively easy to project what will fill that blank, as Molly does in line 9.

Essentially, what we see here is that projection is possible in relatively localized and linear contexts. Thus, in cases where there is a lot of segmental, syntactic, and contextual information that has already been produced, recipients are able to project and help repair an utterance. On the other hand, when there is not much structural information or when there is a mismatch between the segmental and syntactic information, projection will be more difficult (Mayes Forthcoming). This also suggests that anaphorically-oriented questions may be more successful in progressing the ongoing project than cataphorically-oriented questions that seem to involve more guessing on the part of the recipient. However, it seems that recipients use both strategies together.

Shortly after 6, Fred produces an utterance that expresses the idea that he had been trying to get to throughout the telling, which could be considered the point of the story.

(7) The Pops [00:37:59;23 - 00:40:18;23]

01 FD:--> they $(6.8)$ had

02

$03 \mathrm{M}: \quad$ ( (leaning over and pointing toward D))

$04 \quad(2.5)$

05 FD:--> two (14.4) person (6.9) who (13.3) could

$06 \quad(7.6)$

$07 \mathrm{M}$ : [okay, just- complete your thought.]

$08 \mathrm{M}$ : [pointing toward device ]

09 FD:--> ( $\mathrm{sin}$ ) ((side conversation between $\mathrm{M}$ and $\mathrm{a}$ 10 passerby))

(12.2)

12 FD: like

$13 \quad(11.8)$

14 FD:--> (Louise)

$15 \quad(22.6)$

16 FD:--> Armstrong •

17 M: --> okay, what- ((pointing at device))

$18 \mathrm{~F}:$ ( ) ((frowns and shakes left hand))

$19 \mathrm{M}:-->$ that's not-

20 M: --> Armstrong? 


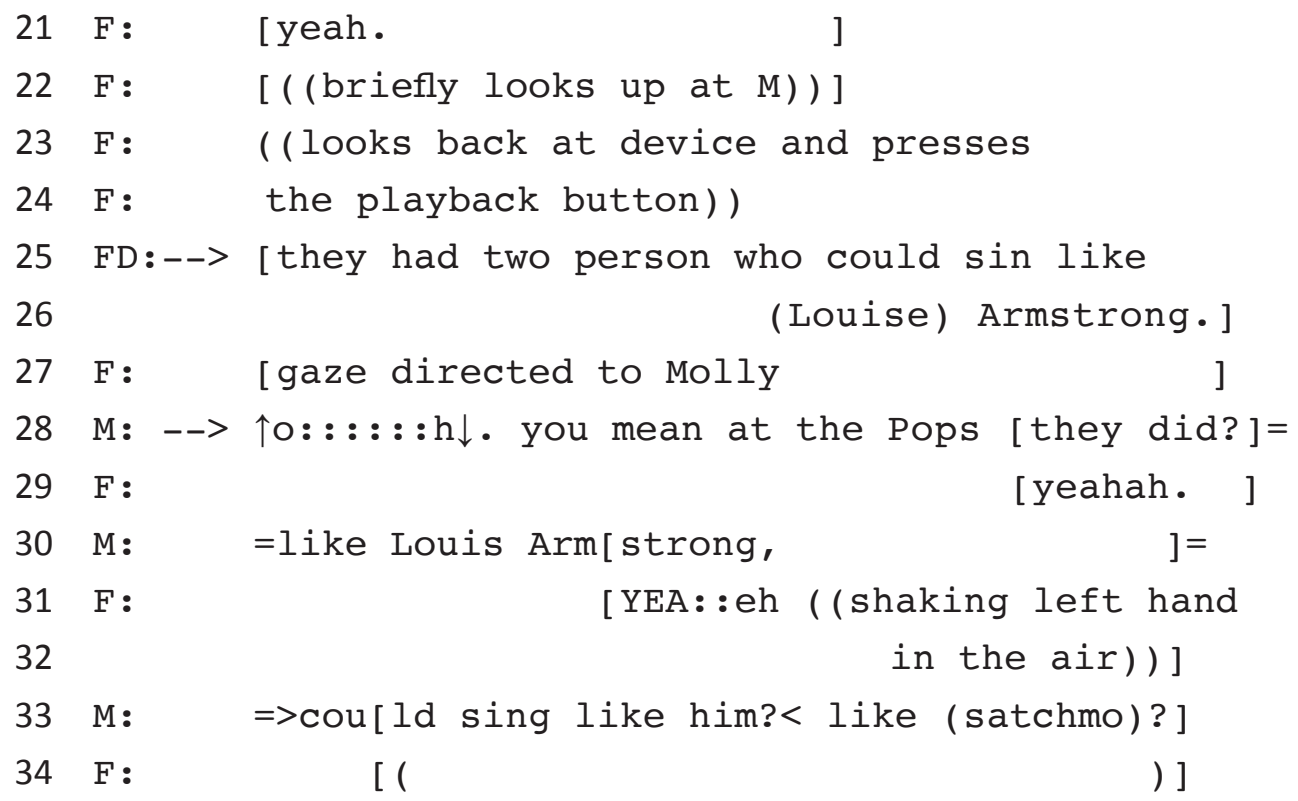

Fred builds the utterance in lines $25-26$ in a step-by-step fashion, which could possibly make the individual words more projectable, as we saw in extract 6 . However, in this case, there are many long delays between the words produced by the device in lines 1-16. In addition, Molly was distracted briefly by a conversation with another person (lines 9-12) and resumed paying attention during the pause in line 13. Thus, when Fred delivers what is essentially the punchline in line 16 Armstrong, she apparently does not initially understand its importance in the story, and begins to ask about it in lines 17, 19, and 20. When Fred repeats the entire utterance in lines 25-26, he shifts his gaze to Molly in line 27 to assess her understanding (Figure 8). At this point, she is finally able to put all of the pieces together, responding with the lengthened change of state token oh and questions in lines 28,30 , and 33 that apparently demonstrate surprise (Wilkinson \& Kitzinger 2006) and can be heard as an appreciative assessment (Figure 9). 


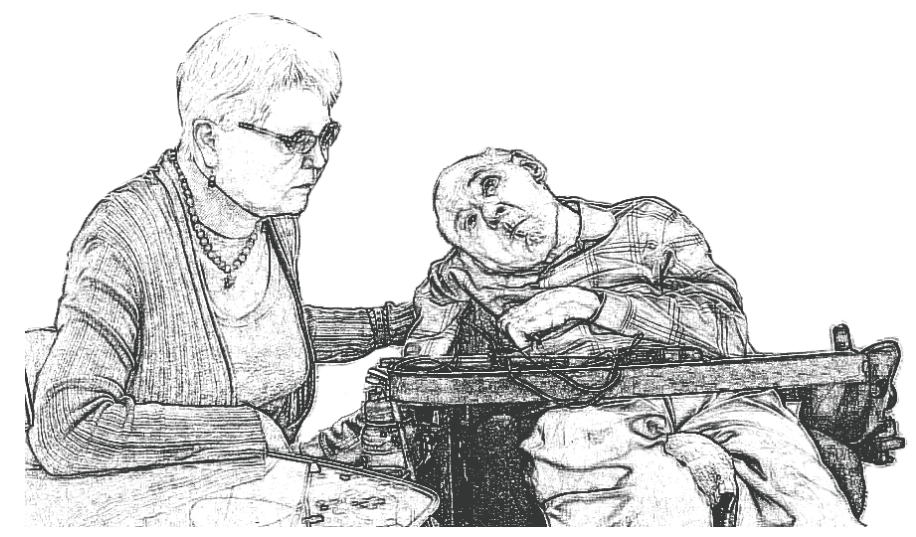

Figure 8. Lines 25-27.

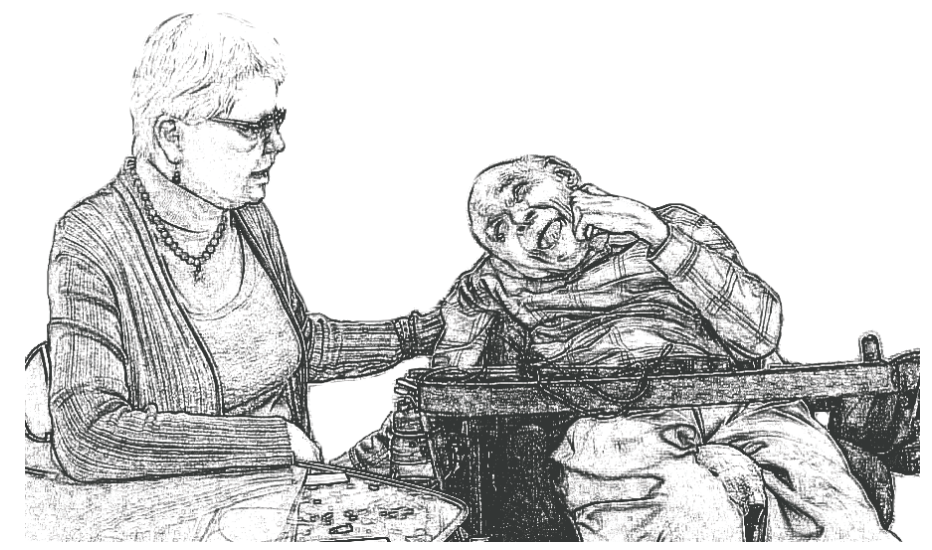

Figure 9. Lines 30-32.

Extract 7 further supports the point made above with respect to extract 6: Projection occurs on a relatively local level, after enough information has accumulated. This example also suggests the impact delays and other distractions have on the recipient's ability to recognize the significance of a particular referent in an ongoing multi-unit turn. Indeed, from lines 5, 9, 14, and 16, the following information had accumulated: They had two person who could sin like Louise Armstrong. Despite the typing errors, given the context that the participants had been discussing Fred's recent experience at the Pops Orchestra performance, it might be thought to be relatively easy to project that the significant information and point of the story is that there were Louis 
Armstrong impersonators performing at the concert. However, even though Molly has heard and repeated the name Armstong (line 20), initially, she does not quite grasp its significance with respect to the story and even asks whether it is related to the Pops (line 28), which had been the topic of conversation for about fourteen minutes at that point. This is likely due to the delays in presenting the entire utterance in which Armstrong is the significant new information, as well as the fact that it took a relatively long time for all of the pieces of information to be presented, which indicates the difficulty of keeping information active over time.

\section{Discussion}

We have examined the co-construction of a story initiated by an AAC-using speaker and presented to an unknowing recipient. Our primary focus was on how the recipient was able to use the available resources to maintain or reestablish intersubjectivity through careful sequential work with the AACusing speaker. Specifically, we were interested in how the recipient constructed questions used for two actions: repair-related actions and actions that could progress the story. Although, in American English, there are various types of questions such as polar questions that can be broken down in terms of form (e.g., interrogative, declarative, and tag questions), Q-word (or wh-) questions, and alternative questions (Stivers 2010), our data contained a mix of polar questions and Q-word questions, with no alternative questions. Our focus was not on these different types of questions, but rather on how the recipient used them to perform the two types of action, mentioned above.

Our findings show that when there was a breakdown in intersubjectivity, the recipient initiated repair-related actions using anaphorically-oriented questions that targeted information that had already been presented by the speaker, and she used whatever resources were available, including segmental, syntactic, and contextual resources to design these questions. When these pieces of information complemented one another, it was easier to reestablish intersubjectivity, as shown in extract 6, but if they did not fit together in a predictable way, it was more difficult to execute repair and reestablish intersubjectivity (e.g., extract 4 ). In this case, the recipient typically produced more general questions such as what subject are we on. As argued, these issues with intersubjectivity point to the fact that the delays in production when a speaker uses an AAC device make it very difficult to project where the speaker is headed, which of course negatively impacts progressivity. However, in attempting to progress the interaction, the recipient relied on another resource: cataphorically-oriented questions that were rather general in nature and seemed designed to follow a trial-and-error, or process of elimination strategy. In our data, this strategy appeared to be less effective in progressing the story and often caused distractions. The questions in extract 1 cookies, oh, to replace the ones (line 15) and in extract 5 Sunday (line 24) do seem to progress the stories underway, but in both cases, there was information that 
had already been presented that helped the recipient narrow the questions enough so that they were successful. In contrast, questions like do you have for the new season? (extract 4, line 45) and so now you don't go til November? (extract 5, line 34) were distractions that could potentially further delay progress if the speaker had spent time answering them.

These examples also show that the AAC-using speaker is well aware of the problems in eliciting help from his interlocutors. Indeed, he used gesture, and especially eye gaze, to see if the recipient understood and possibly to prompt her to demonstrate her understanding through candidate understandings and other repair-oriented actions. On the other hand, in cases where her questions were unrelated to his project, he responded with actions that demonstrated this such as raising his eye brows, (extract 3 , line 5 ), orienting his body toward the device and continuing to type (extract 3 , line 6 ), gesturing (extract 4 , lines 46-47 and 49-50), and sometimes by laughing (extract 5, line 32 ).

\section{Conclusions}

Examining AAC interaction reveals much about how much interactional work is necessary when one (or more) conversational participants cannot speak. Despite the fact that high-tech electronic devices have done much to help people with complex communication disabilities voice their utterances, communication mediated by such devices is by no means simple or straightforward. General conversational principles that most speakers take for granted such as maintaining intersubjective understanding, using the tools of reference and repair, can become very difficult when some of the resources used in everyday talk are not available to the speaker, thereby limiting the recipient's ability to project. Of course, problems with projection are relevant to the current turn, but they become even more complex when the speaker initiates an extended project like storytelling. Still, analyzing the interaction in this case study reveals how resourceful people are at adapting existing resources such as questions, eye gaze, gestures, and bodily movements in specific sequentially organized ways, designed to satisfy their drive to understand one another and progress the project underway. 


\section{Appendix}

Transcription Key

\begin{tabular}{|c|c|c|c|}
\hline $\begin{array}{l}\text { Discourse } \\
\text { symbol }\end{array}$ & Meaning & $\begin{array}{l}\text { Character } \\
\text { symbol }\end{array}$ & Meaning \\
\hline [] & Overlapping talk & FD & $\begin{array}{l}\text { Fred's utterances produced } \\
\text { via the AAC device }\end{array}$ \\
\hline , & $\begin{array}{l}\text { Falling intonation } \\
\text { Slightly rising intonation }\end{array}$ & $\mathrm{F}$ & $\begin{array}{l}\text { Fred's vocal utterances, } \\
\text { gaze, or gestures }\end{array}$ \\
\hline$?$ & $\begin{array}{l}\text { Level intonation } \\
\text { Rising intonation }\end{array}$ & $\mathrm{M}$ & $\begin{array}{l}\text { Molly's utterances, gaze, } \\
\text { or gestures }\end{array}$ \\
\hline $\begin{array}{l}(.) \\
(\# . \#)\end{array}$ & $\begin{array}{l}\text { Small pause } \\
\text { Pause counted in seconds } \\
\text { and milliseconds }\end{array}$ & & \\
\hline${ }^{\circ}$ word ${ }^{\circ}$ & Quiet & & \\
\hline WOrd & Stressed word & & \\
\hline W-O-R- & Spelled out word & & \\
\hline$((())$ & Transcriber's comments & & \\
\hline hehe & Laughter & & \\
\hline wo:rd & Syllable lengthening & & \\
\hline$\uparrow \downarrow$ & $\begin{array}{l}\text { Raised or lowered pitch } \\
\text { relative to normal pitch }\end{array}$ & & \\
\hline ( ) & Undecipherable utterance & & \\
\hline$-->$ & Turns for analysis & & \\
\hline$. \mathrm{h} / \mathrm{h}$. & Inhalation / exhalation & & \\
\hline wor- & Cut off syllable & & \\
\hline
\end{tabular}




\section{Notes}

* We are very grateful to our study participants for generously donating their time. We also acknowledge the support of the University of Wisconsin - Milwaukee's Center for 21st Century Studies for a Transdisciplinary Challenges Award, which funded the data collection and transcription that made this study possible. In addition, we thank the editors and reviewers for comments on a previous draft.

1 Fred and Molly are pseudonyms.

2 Prior to that, he had used a low-tech type of AAC, involving a spelling board.

3 See Lerner and Kitzinger (2015) for more about repair prefacing in typical English interaction.

4 Molly may have requested this story to provide additional contextual background for the researchers.

\section{References}

Auer, Peter. 2005. Projection in interaction and projection in grammar. Text \& Talk 25(1), 7-36.

Auer, Peter. 2009. Projection and minimalistic syntax in interaction. Discourse Processes 46(2-3), 180-205.

Bloch, Steven. 2011. Anticipatory other-completion of augmentative and alternative communication talk: A conversation analysis study. Disability and Rehabilitation 33(3), 229-42.

Bloch, Steven and Ray Wilkinson. 2004. The understandability of AAC: A conversation analysis study of acquired dysarthria. Augmentative and Alternative Communication 20(4), 272-82.

Bloch, Steven and Ray Wilkinson. 2009. Acquired dysarthria in conversation identifying sources of understandability problems. International Journal of Language and Communication Disorders 44(5), 769-83.

Chevalier, Fabienne. H. G., and Rebecca Clift. 2008. Unfinished turns in French conversation: Projectability, syntax and action. Journal of Pragmatics 40(10), 1731-52.

Drew, Paul. 1984. Speakers' reporting in invitation sequences. Structures of social action: Studies in conversation analysis, ed. by J. Maxwell Atkinson and John Heritage, 129-51. Cambridge: Cambridge University Press.

Drew, Paul. 1997. 'Open' class repair initiators in response to sequential sources of troubles in conversation. Journal of Pragmatics 28, 69-101.

De Fina, Anna and Alexandra Georgakopoulou. 2015. Introduction. The handbook of narrative analysis, ed. by Anna De Fina and Alexandra Georgakopoulou, 1-17. West Sussex, UK: John Wiley \& Sons.

Ford, Cecilia E. and Sandra A. Thompson. 1996. Interactional units in conversation: Syntactic, intonational, and pragmatic resources for the management of turns. Interaction and grammar, ed. by Elinor Ochs, Emanuel A. Schegloff, and Sandra A. Thompson, 134-84. (Studies in Interactional Sociolinguistics 13) Cambridge: Cambridge University Press.

Freed, Alice and Susan Ehrlich. (eds.) 2010. "Why do you ask?" The function of questions in institutional discourse. Oxford: Oxford University Press.

Georgakopoulou, Alexandra. 2006. Thinking big with small stories in narrative and identity analysis. Narrative Inquiry 16(1), 122-30. 
Georgakopoulou, Alexandra. 2007. Small stories, interaction and identities. Amsterdam: John Benjamins.

Goodwin, Charles. 1979. The interactive construction of a sentence in natural conversation. Everyday language: Studies in ethnomethodology, ed. by George Psathas, 97- 121. New York: Irvington Publishers.

Goodwin, Charles. 1984. Notes on story structure and the organization of participation. Structures of social action: Studies in conversation analysis, ed. by J. Maxwell Atkinson and John Heritage, 225-46. Cambridge: Cambridge University Press.

Goodwin, Charles. 2015. Narrative as talk-in-interaction. The handbook of narrative analysis, ed. by Anna De Fina and Alexandra Georgakopoulou, 195-218. West Sussex, UK: John Wiley \& Sons.

Graf, Eva-Maria, Frédérick Dionne and Thomas Spranz-Fogasy. 2020. How to investigate the local and global change potential of questioning sequences in executive coaching? A call for interdisciplinary research. Scandinavian Studies in Language 11(1), 214-238.

Hayano, Kaoru. 2013. Question design in conversation. The handbook of conversation analysis, ed. by Jack Sidnell and Tanya Stivers, 395-414. Malden, MA: Blackwell Publishing.

Hayashi, Makoto. 2004. Projection and grammar: Notes on the action-projecting use of the distal demonstrative are in Japanese. Journal of Pragmatics 36, 1337-74.

Helasvuo, Marja-Liisa. 2004. Shared syntax: the grammar of co-constructions. Journal of Pragmatics 36, 1315-36.

Heritage, John. 2007. Intersubjectivity and progressivity in person (and place) reference. Person reference in interaction: Linguistic, cultural and social perspectives, ed. by Tanya Stivers and Nick J. Enfield, 255-80. (Language, culture and cognition 7) Cambridge: Cambridge University Press.

Heritage, John and Steven Clayman. 2010. Talk in action: Interactions, identities, and institutions. West Sussex, UK: Wiley-Blackwell.

Higginbotham, Jeffery D. and Kevin Caves. 2002. AAC performance and usability issues: The effect of AAC technology on the communicative process. Assistive Technology 14(1), 45-57.

Jefferson, Gail. 2004. Glossary of transcript symbols with an introduction. Conversation analysis: Studies from the first generation, ed. by Gene H. Lerner, 13-31. Amsterdam: John Benjamins.

Keevallik, Leelo. 2012. Compromising progressivity: 'No'-prefacing in Estonian. Pragmatics 22(1), 119-46.

Koenig, Christopher J. 2006. Oblique interventions: A question-initiated sequence in multi-unit turn environments. Unpublished manuscript, online: https://doi. org/10.13140/rg.2.1.2381.9284.

Labov, William. 1972. Language in the inner city: Studies in the Black English vernacular. Philadelphia: University of Pennsylvania Press.

Lerner, Gene H. 1996. On the "semi-permeable" character of grammatical units in conversation: Conditional entry into the turn space of another speaker. Interaction and grammar, ed. by Elinor Ochs, Emanuel A. Schegloff, and Sandra A. Thompson, 238-76. (Studies in Interactional Sociolinguistics 13) Cambridge: Cambridge University Press.

Lerner, Gene H. and Celia Kitzinger. 2015. Or-prefacing in the organization of self-initiated repair. Research on Language and Social Interaction 48(1), 58-78. 
Luo, Fei, Lisa Bardach, Jennifer Cornish, and Jeffrey D. Higginbotham. 2008. Personal narrative telling of AAC users with ALS. Poster session presented at the American Speech Language and Hearing Association meeting, Chicago, IL.

Mandelbaum, Jenny. 2013. Storytelling in conversation. The handbook of conversation analysis, ed. by Jack Sidnell and Tanya Stivers, 492-508. Malden, MA: Blackwell Publishing.

Mayes, Patricia. Forthcoming. Nouns and noun phrases in Other-initiated repair in English atypical interaction: A case study of Augmentative and Alternative Communication. The pragmatics of the noun phrase across languages: An emergent unit in interaction, ed. by Yoshi Ono and Sandra A. Thompson, 179-207. Amsterdam: John Benjamins.

Müller, Eve and Gloria Soto. 2002. Conversation patterns of three adults using aided speech: Variations across partners. Augmentative and Alternative Communication 18(2), 77-90.

Ochs, Elinor, and Lisa Capps. 2001. Living narrative: Creating lives in everyday storytelling. Cambridge, MA: Harvard University Press.

Perkins, Lisa. 2003. Negotiating repair in aphasic conversation: Interactional issues. Conversation and brain damage, ed. by Charles Goodwin, 147-62. Oxford: Oxford University Press.

Sacks, Harvey. 1978. Some technical considerations of a dirty joke. Studies in the organization of conversational interaction, ed. by Jim Schenkein, 249-70. New York: Academic Press.

Sacks, Harvey, Emanuel A. Schegloff, and Gail Jefferson. 1974. A simplest systematics for the organization of turn-taking for conversation. Language 50(4), 696-735.

Schegloff, Emanuel A. 1990. On the organization of sequences as a source of 'coherence' in talk-in-interaction. Conversational organization and its development, ed. by Bruce Dorval, 51-77. Norwood, New Jersey: Ablex.

Schegloff, Emanuel A. 2007. A primer for conversation analysis: Sequence organization. Cambridge: Cambridge University Press.

Sidnell, Jack. 2010. Conversation analysis: An introduction. Oxford: Wiley-Blackwell. Stivers, Tanya. 2008. Stance, alignment and affiliation during storytelling: When nodding is a token of affiliation. Research on Language and Social Interaction 41(1), $31-57$.

Stivers, Tanya. 2010. An overview of the question-response system in American English conversation. Journal of Pragmatics 42(10), 2772-81.

Stivers, Tanya and Jeffrey D. Robinson. 2006. A preference for progressivity in interaction. Language in Society 35(3), 367-92.

Tranekjær, Louise. 2020. LEAN diversity management in practice: The multi-functionality of questions as a resource to ensure understanding, participation and procedural compliance in a diverse workplace. Scandinavian Studies in Language 11(1), 83-116.

Wilkinson, Sue and Celia Kitzinger. 2006. Surprise as an interactional achievement: Reaction tokens in conversation. Social Psychology Quarterly 69(2), 150-82.

Worsøe, Line Brink and Thomas Wiben Jensen. 2020. Questioning questions in psychotherapeutic practice: The dialogical dynamics of change in therapy through clients questioning therapists. Scandinavian Studies in Language 11(1), 279-317. 